\title{
A portable and low-cost parallel-plate capacitor sensor for alkali and heavy metal ions detection
}

\author{
Septia Kholimatussadiah* and Tri Anggono Prijo \\ Department of Physics, Faculty of Science and Technology \\ Universitas Airlangga, Surabaya, Indonesia \\ *septia.k@fst.unair.ac.id
}

Received 17 May 2018; Revised 28 June 2018; Accepted 6 July 2018; Published 3 August 2018

\begin{abstract}
A portable and low-cost design of parallel-plate capacitor sensor is proposed and investigated for detection of heavy and alkali metal ions concentration in liquid solution. The application of a thin and long-sided parallel PCB plate allows one to measure the dielectric response of each sample through capacitive sensing technique. The measurements were based on the peak output voltage corresponding to the capacitance of the output measured by an oscilloscope with metal ions concentration of the solution varying from 0 to $10 \mathrm{ppm}$ and input frequency ranging from $1 \mathrm{kHz}$ to $10 \mathrm{MHz}$. The ICF of $\mathrm{Li}, \mathrm{Na}$ and $\mathrm{K}$ in chloride solution was $2.4,2.1$ and $1.9 \mathrm{MHz}$, respectively. The ICF of $\mathrm{Na}$ and $\mathrm{K}$ in hydroxide solution was $1.5 \mathrm{MHz}$ and $1.1 \mathrm{MHz}$, respectively, while the ICF of $\mathrm{Pb}\left(\mathrm{NO}_{3}\right)_{2}$ was $490 \mathrm{kHz}$. The detected ICF was applied to further construct the portable sensor system, which is simple in design, low-cost in fabrication and easy to operate. The finding of ICF of each chemical element is necessary to solve the selectivity challenge of the capacitance-based sensor, which will be appropriate for chemical, environmental and engineering applications.
\end{abstract}

Keywords: Capacitive sensing; capacitor sensor; characteristic frequency; metal ions detection; parallel-plate capacitor.

\section{Introduction}

Capacitive sensing ${ }^{1}$ is becoming an increasingly popular technology to replace optical and mechanical methods for motion detection applications, ${ }^{2}$ material analysis, ${ }^{3}$ and liquid level ${ }^{4}$ sensing. The main advantage of capacitive sensing over other methods is to detect a variety of materials (leather, plastic, metal and liquid), simple system design, comfortable and practical operation and low cost, so it is possible to be mass-produced. ${ }^{1}$ In addition, in the field of material analysis, the methods that are often used are chemical analysis methods such as spectrophotometry and chromatography. The drawback is that the sample of the chemical composition should be taken and tested in the laboratory, so it is not possible to test it in real-time in the field. This constraint can be avoided by utilizing capacitive sensing techniques for certain samples requiring real-time and continuous measurements, such as the measurement of salinity of seawater and the level of pollution of waste at aquatic sources.

Capacitive sensing is a sensor that works by using the principle of capacitor. ${ }^{1}$ One of the simplest capacitor forms is the parallel-plate capacitor. The parallel-plate capacitor consists of two conductor plates with a particular surface area, which is positioned parallel to each other and separated by a certain distance. Since the cross-sectional area and the spacing between the two plates are set constant, the only factor that will affect the measured capacitance value is the dielectric constant of the material. This is the basis for the application of parallel-plate capacitors for material analysis.
The measurement of the dielectric response can provide a valuable understanding of the electrostatic and electrokinetic properties of the colloidal dispersion and its constituent particles. ${ }^{5}$ The dielectric constant will be affected by many factors, including material type, concentration, solvent polarity, temperature, humidity and air pressure. ${ }^{1,6}$ Since the dielectric constant is affected by moisture, then by assuming that the air pressure and the temperature is constant, the capacitance method can be used as an air humidity sensor. ${ }^{7-10}$ In practice, however, external factors such as temperature, humidity and air pressure in the laboratory are considered constant and can be ignored in the calculations.

In addition to some of the advantages they has, parallelplate sensors have a significant disadvantage in terms of selectivity. The poor selectivity of parallel-plate sensors is due to the physical properties of the parallel-plate capacitor, i.e., the capacitance value of the sensor depends on the dielectric constant value of the measured material. The dielectric constant expresses the permittivity of the flux relative to a vacuum, i.e., the density of the electrostatic flux when given a certain external electrical field. The dielectric constant is influenced by various factors both internal and external, such as the type of material, concentration, polarity solvent, temperature, humidity and pressure. ${ }^{11}$ In practice, the measurement of the capacitance response is sensitive to the input signal frequency. ${ }^{1}$ This frequency, which is, also the characteristic of each material, is after this referred to as the internal characteristic frequency (ICF). To overcome the selectivity problem of the parallel-plate capacitor sensor,

This is an Open Access article published by World Scientific Publishing Company. It is distributed under the terms of the Creative Commons Attribution 4.0 (CC-BY) License. Further distribution of this work is permitted, provided the original work is properly cited. 
the material analysis needs to be done at this particular frequency. Therefore, it is necessary to find out the ICF of each material.

This study aims to design a sensor based on parallel-plate capacitors that can detect certain elements such as alkali and heavy metals ions, identifying variations of concentration, as well as finding the frequency characteristics of these elements. The samples used in this study are several types of alkali and heavy metals solutions with various concentrations, namely $\mathrm{LiCl}, \mathrm{NaCl}, \mathrm{KCl}, \mathrm{NaOH}, \mathrm{KOH}$ and $\mathrm{Pb}\left(\mathrm{NO}_{3}\right)_{2}$. The proposed sensor measured the output voltage, which is influenced by the dielectric changes of the samples. This technique offers simplicity, reliability and continuous measurement capability.

\section{Experimental Details}

\subsection{Sensor design and fabrication}

The process of making a parallel-plate capacitor sensor begins with the preparation of copper-coated fiber plate in the form of printed circuit board (PCB) plate as the main body of the sensor. The selection of PCB plate is based on the criteria of thin flat metal requirement but has a high rigidity as a sensor support. These requirements are filled with PCB made of a nonconductive fiber material with evenly coated metal layers. To facilitate the preparation stage, PCB plate was cut to the same size, i.e., $5 \mathrm{~cm}$ long and $1 \mathrm{~cm}$ wide. The etching process was done to obtain the desired broad size. Before etching process, the $\mathrm{PCB}$ is insulated to prevent its reaction with the $\mathrm{FeCl}_{3}$ solution. The size of the insulation is $4 \mathrm{~cm}$ long and $0.5 \mathrm{~cm}$ wide to obtain a total of $2 \mathrm{~cm}^{2}$ cross-sectional area as illustrated in Fig. 1. After the etching process was finished, two identical PCB plates of the exact same size, as expected were obtained. The next step is to install the connecting cable on each plate through the soldering process. Soldering must be neat and thorough, so as not to interfere with the coating process with an insulating material. After the connecting cable is properly installed, then the coating is provided with a permanent insulating material to prevent the conductivity effect of the solution. The insulating layer should be thin and flat, so the changes in dielectric constant due to the insulator thickness can be negligible. The two plates then were placed parallel to each other yet separated by a distance of $4 \mathrm{~mm}$.

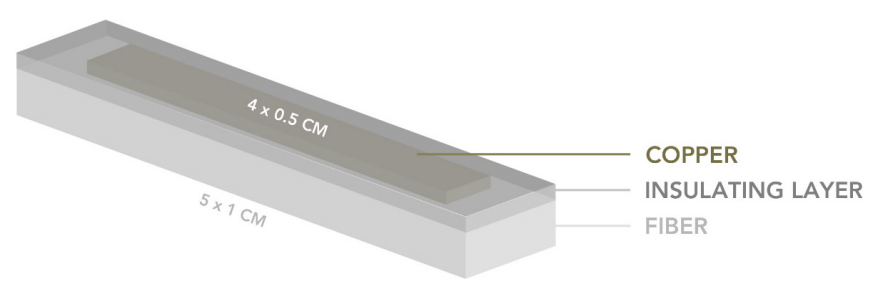

Fig. 1. Diagram of parallel-plate capacitor sensor.

\subsection{Metal ion solution}

Metal ion solutions were prepared from analytical grade lithium chloride $(\mathrm{LiCl})$, sodium chloride $(\mathrm{NaCl})$, potassium chloride $(\mathrm{KCl})$, sodium hydroxide $(\mathrm{NaOH})$, potassium hydroxide $(\mathrm{KOH})$ and lead dinitrate $\left(\mathrm{Pb}\left(\mathrm{NO}_{3}\right)_{2}\right)$ (Emsure; $98 \%$, metals basis) using deionized water. Metal powders were weighed with an analytical balance (Fujitsu FS-AR210), dissolved in a certain volume of deionized water until the metal ions content in each solution were in the range of $1-10 \mathrm{ppm}$. Although humidity and temperature changes affect the dielectric measurement, the humidity and temperature are considered negligible, and the temperature is kept constant at $25^{\circ} \mathrm{C}$ during the experiment.

\subsection{Output voltage and measurements}

To find out the optimum response of the parallel-plate capacitor sensor, a series of measurements were conducted. The measurements aim to determine the linear relationship between the measured capacitance to the content of the metal ions solution. $\mathrm{LiCl}, \mathrm{NaCl}, \mathrm{KCl}, \mathrm{NaOH}, \mathrm{KOH}$ and $\mathrm{Pb}\left(\mathrm{NO}_{3}\right)_{2}$ solutions with concentrations of $1-10 \mathrm{ppm}$ were used as the samples. To get the ICF of each solution, the input frequency was varied from $1 \mathrm{kHz}$ up to $10 \mathrm{MHz}$. The sinusoidal waveform was selected because it does not undergo distortion and change when reacting with the capacitive circuit. It is known that sinusoidal wave function will remain unchangeable when interacting with differentiator or integrator circuit. ${ }^{12}$ The input signal from a signal generator (Iwatsu Electronic Co., Ltd. FG-350) is connected to the voltage divider circuit, which is composed of the series circuit between the capacitor and the reference capacitor or better known as De Sauty Bridge. Changes in the capacitance can be observed from the output voltage at the terminal between the capacitor sensor and the reference capacitor. Measurement of output voltage was done by using a digital oscilloscope (Atten $(\mathrm{B})$ Instruments AT7340 $40 \mathrm{MHz}$ ). The measurement result is the output voltage value as a function of the given sinusoidal wave frequency and the metals ions content in the solution. The experimental setup is shown in Fig. 2.

\section{Results and Discussion}

Figures 3(a)-3(f) shows the output voltage against the variation of concentration of each metal ion solution. As shown in the figure, the output voltage of the sensor linearly increases as the concentration of the metal solution increases. The results show the degree of linearity of the sensor are 0.9946, 0.9943, 0.9951, 0.8830, 0.9667 and 0.9699 for $\mathrm{LiCl}$, $\mathrm{NaCl}, \mathrm{KCl}, \mathrm{NaOH}, \mathrm{KOH}$ and $\mathrm{Pb}\left(\mathrm{NO}_{3}\right)_{2}$ solutions, respectively. The sensor performance is summarized in Table 1. The sensitivity ${ }^{1,13}$ defines the detection limit, which is the smallest concentration that can be sensed by the sensor, and the best sensitivity is obtained at $0.4 \mathrm{ppm}$ for $\mathrm{KCl}$ solution. 

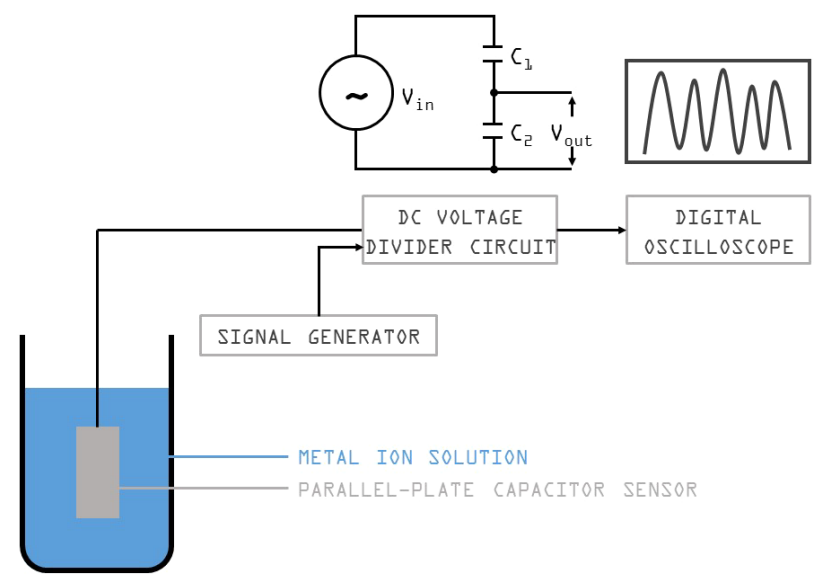

Fig. 2. Experimental setup for the proposed parallel-plate capacitor sensor for metal ion detection.

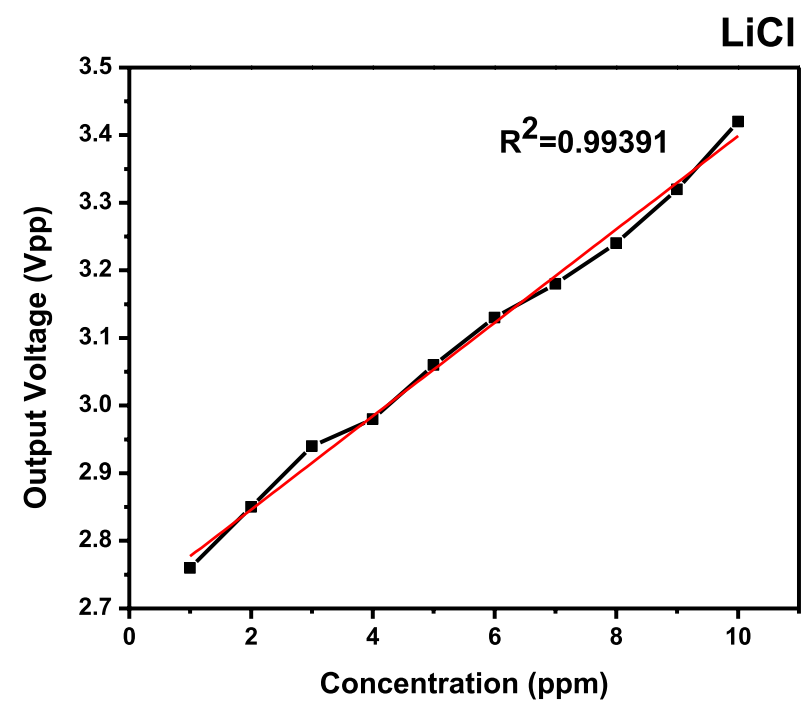

(a)

$\mathrm{KCl}$

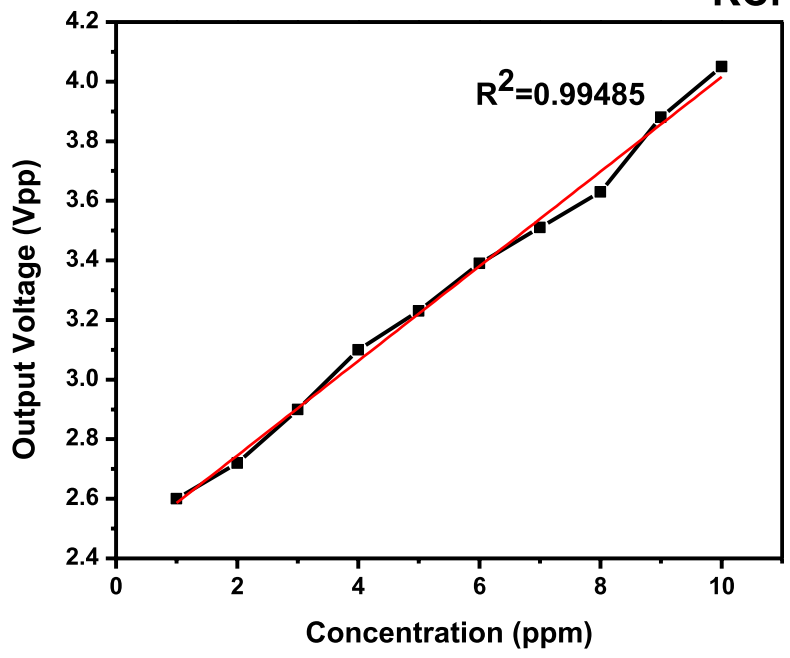

(c)
The resolution, ${ }^{1,13}$ on the other hand, is the smallest change that can be detected by the sensor and is obtained at $1 \mathrm{mV}$ for all solutions. The sensor's degree of linearity with the majority value of more than $95 \%$ indicates that the parallel-plate capacitor sensor provides a good performance and can be used as an alternative sensor to evaluate the concentration of the solution.

The output voltage that increases linearly with the increasing concentration can be explained using the dielectric concept of the material. ${ }^{14}$ Higher ion concentration in the solution reduces the net electric field because the electric dipole within the molecules tends to oppose the external electric field (Fig. 4). ${ }^{15}$ As a result, the net electric field will be reduced. The reducing net electric field is described as high dielectric constant; higher dielectric constant indicates higher capacitance. Consequently, the voltage output

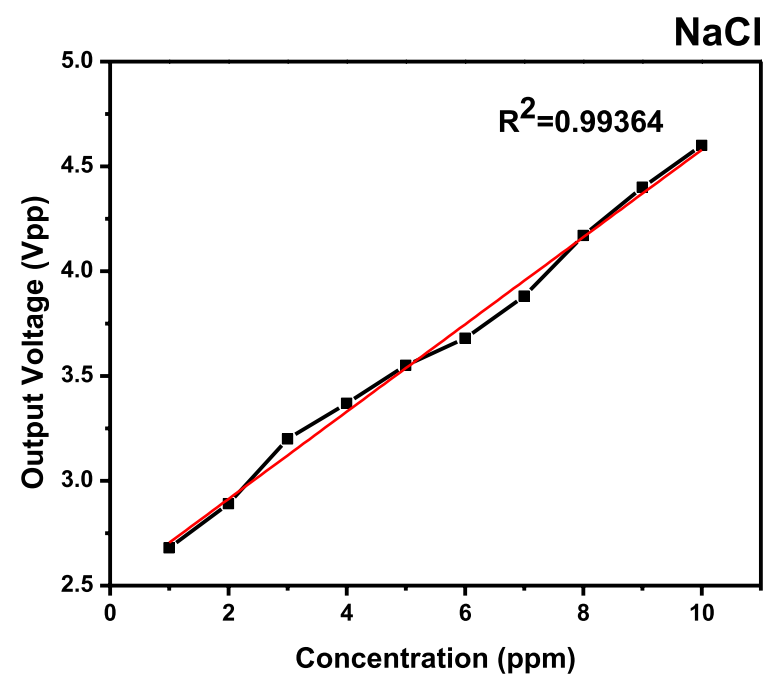

(b)

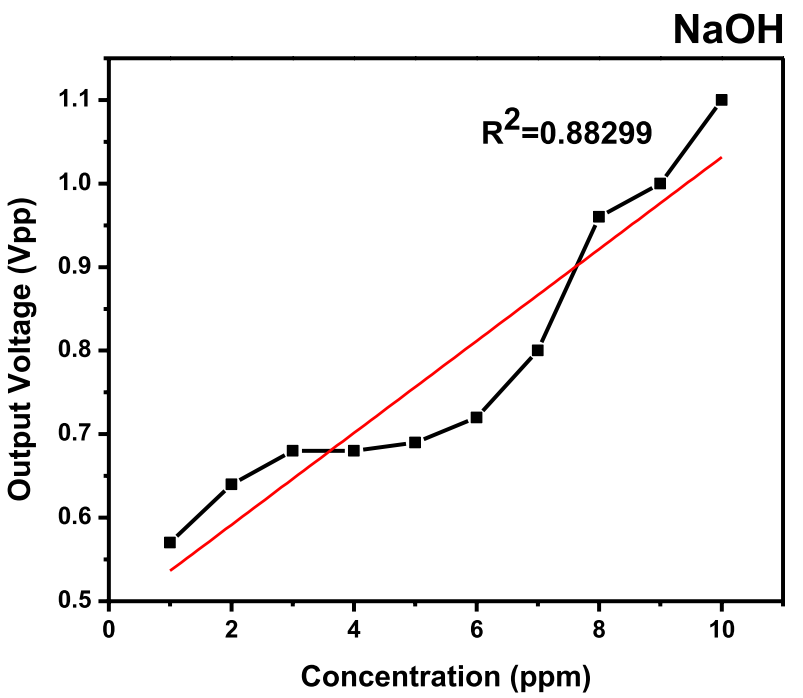

(d)

Fig. 3. Output voltage against metals ions concentration for (a) $\mathrm{LiCl}$, (b) $\mathrm{NaCl}$, (c) $\mathrm{KCl}$, (d) $\mathrm{NaOH}$, (e) $\mathrm{KOH}$ and (f) $\mathrm{Pb}\left(\mathrm{NO}_{3}\right)_{2}$ solution. 


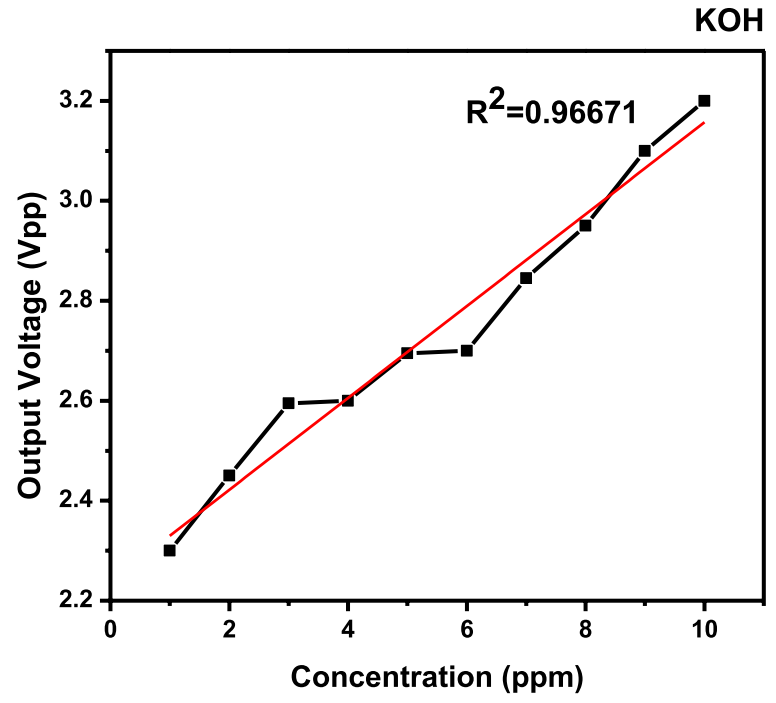

(e)

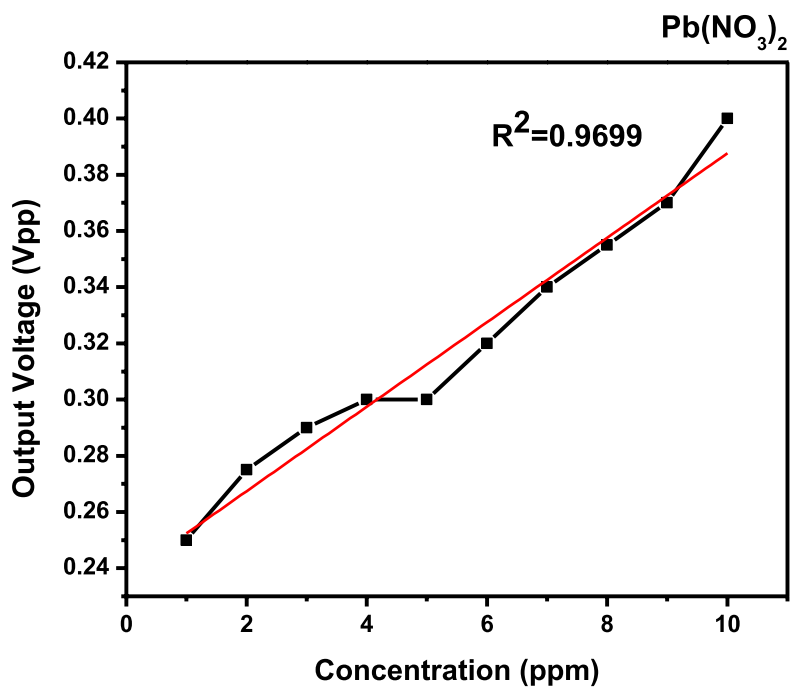

(f)

Fig. 3. (Continued)

Table 1. The performance of parallel-plate capacitor sensor.

\begin{tabular}{|c|c|c|c|c|c|c|}
\hline \multirow[b]{2}{*}{ Parameter } & \multicolumn{6}{|c|}{ Value } \\
\hline & $\mathrm{LiCl}$ & $\mathrm{NaCl}$ & $\mathrm{KCl}$ & $\mathrm{NaOH}$ & $\mathrm{KOH}$ & $\mathrm{Pb}\left(\mathrm{NO}_{3}\right)_{2}$ \\
\hline Linearity (\%) & 99.46 & 99.43 & 99.51 & 88.30 & 96.67 & 96.99 \\
\hline Sensitivity (ppm/mV) & 14.5 & 4.8 & 0.4 & 18.8 & 66.5 & 10.9 \\
\hline Resolution (mV) & 1 & 1 & 1 & 1 & 1 & 1 \\
\hline $\begin{array}{l}\text { Measurement } \\
\text { range (ppm) }\end{array}$ & $0-10$ & $0-10$ & $0-10$ & $0-10$ & $0-10$ & $0-10$ \\
\hline
\end{tabular}

increases, which will be used as an indicator of different concentration of ion metal solution in this study.

Figures 5(a)-5(f) show the output voltage against variation of the frequency of each metal ion solution. As shown in the figure, the output voltage-to-frequency response for each

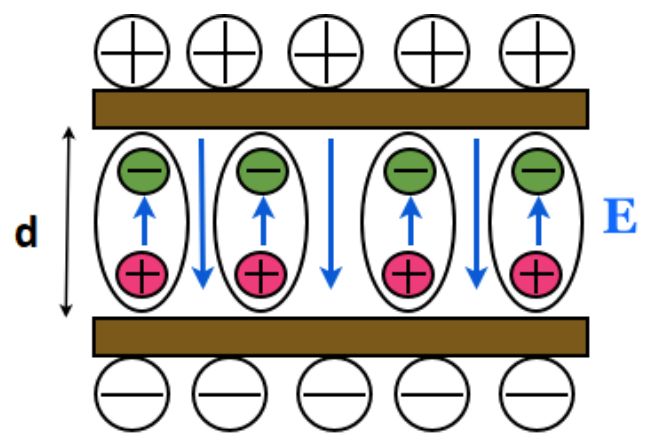

Fig. 4. Illustration between dipole moment of dielectric material and external electric field inside a parallel-plate capacitor (d: distance between capacitor's plates; E: electric field). solution varies. The top of each plot shows the optimal frequency that gives the highest output voltage in each solution. From Fig. 5, it can be found that the optimal frequency for $\mathrm{LiCl}, \mathrm{NaCl}, \mathrm{KCl}, \mathrm{NaOH}, \mathrm{KOH}$ and $\mathrm{Pb}\left(\mathrm{NO}_{3}\right)_{2}$ solutions is $2.4 \mathrm{MHz}, \quad 2.1 \mathrm{MHz}, \quad 1.9 \mathrm{MHz}, \quad 1.5 \mathrm{MHz}, \quad 1.1 \mathrm{MHz}$ and $490 \mathrm{kHz}$, respectively. This optimal frequency, which gives the highest output voltage together with the best linearity degree, is called the ICF. The results from Fig. 5 also proved that the ICF does not change over the variation of concentration, shown by the peak output voltage, which remains constant at the same frequency for all variations in the concentration of the solution used. Hence, it can be concluded that the ICF is a characteristic property of a specific material. The linearly decreased ICFs from $\mathrm{LiCl}$ to $\mathrm{KCl}$, and from $\mathrm{NaOH}$ to $\mathrm{Pb}\left(\mathrm{NO}_{3}\right)_{2}$ agree with the theoretical basis, which says that the ICF of the material will be inversely proportional to the reduced mass of the material. ${ }^{16,17}$ In short, we can expect larger molecules to have smaller ICF and vice versa.

The correlation between ICFs and the highest output voltage can be described using the quantum properties of the material. The electrical signal frequency is a description of the changes of the electric field over time, resulting in a change in the electric dipole orientation of the metal ions solution. The electric dipole in the solution always tends to oppose the external electric field ${ }^{15}$ or attempts to maintain its internal electric dipole orientation (Fig. 4). At certain frequencies, the dipole orientation will be in equilibrium between the moment of the force due to the external electric field and the opposing internal force, so that the dipole orientation becomes stable and the solution has a certain polarity. This is called the polarization effect. In polarized conditions, the solution will become ferroelectric, having its 
maximum dielectric value. ${ }^{14}$ This means that the capacitance of the sensor will be of utmost value, which is indicated by the maximum output voltage when given a specific frequency, as already proved in this study. This certain frequency is associated with the vibration and rotation frequency of the molecules, at which, the value will be inversely proportional to its moment of inertia. ${ }^{16,17}$ In other words, the ICF of the molecules is inversely proportional to its mass.

Finally, we have successfully fabricated the capacitor sensor which can detect the concentration difference in various metal ion solutions. The sensor design as well as the method of fabrication is very simple and utilizes low-cost materials. This design offers simplicity, reliability and continuous measurement capability. However, despite its advantages as previously mentioned, the major drawback of this sensor is its selectivity issue. All the metal ion solutions used in this study are homogenous solutions, therefore, further research to study the sensor's capability to detect the concentration of a certain ion in a heterogeneous solution is necessary. Further improvement of the sensor's design to increase its sensitivity and detection range also needs to be done.

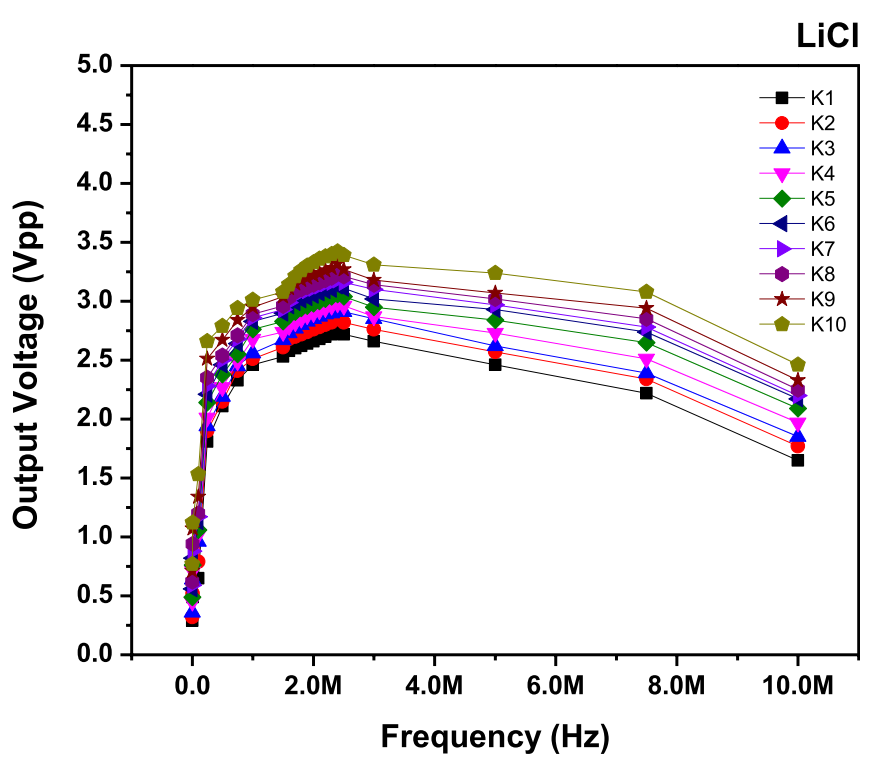

(a)

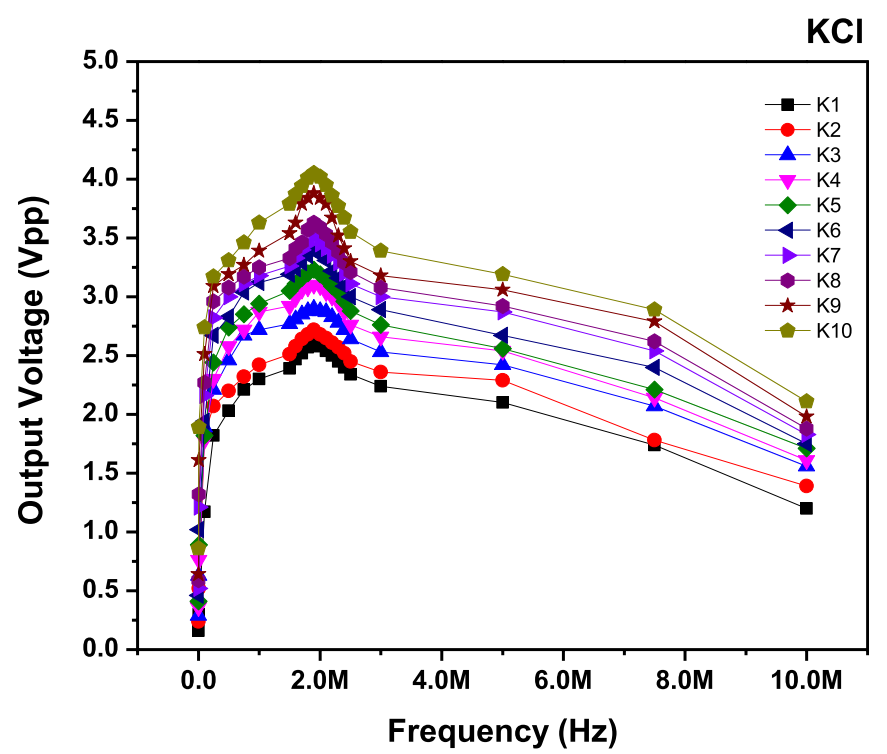

(c)

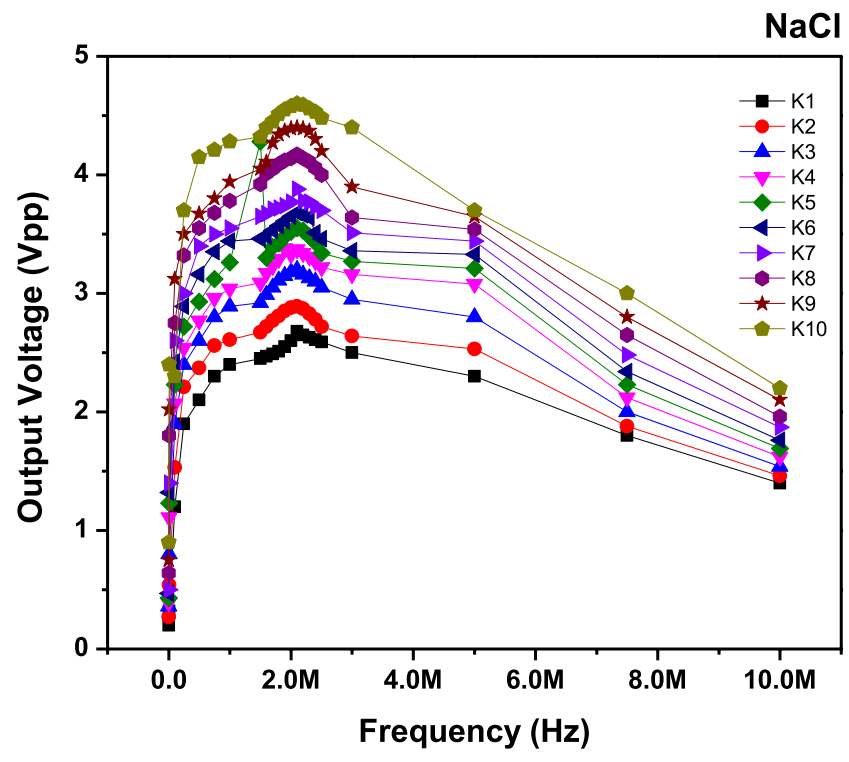

(b)

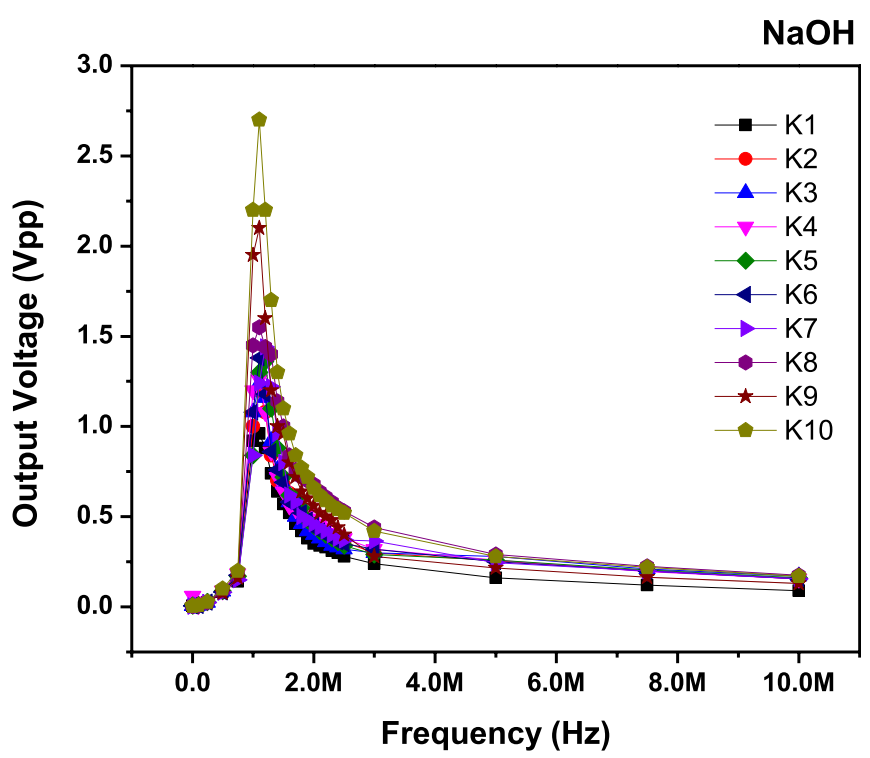

(d)

Fig. 5. Output voltage (Vpp) against input frequency (Hz) for (a) $\mathrm{LiCl}$, (b) $\mathrm{NaCl}$, (c) $\mathrm{KCl}$, (d) $\mathrm{NaOH}$, (e) $\mathrm{KOH}$ and (f) $\mathrm{Pb}\left(\mathrm{NO}_{3}\right)_{2}$ metals solution. 


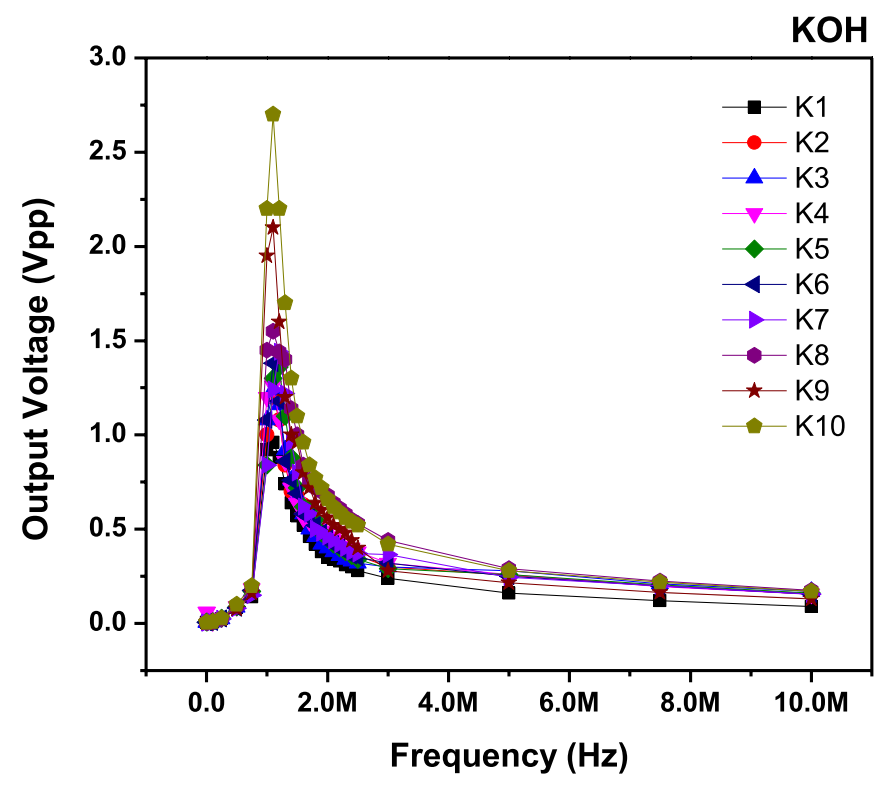

(e)

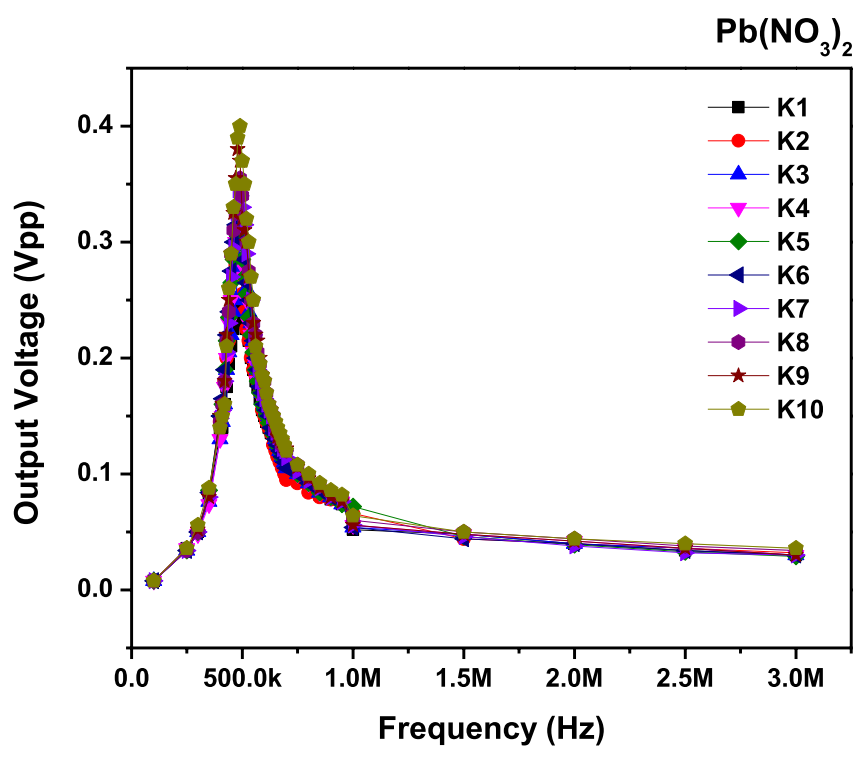

(f)

Fig. 5. (Continued)

\section{Conclusion}

A portable and low-cost sensor is proposed and investigated for the detection of metal ion solution in various concentrations. The main body of the sensor was made of a pair of copper-coated PCB plates connected to the larger capacitor as the voltage divider circuit. For a concentration change from 0 to $10 \mathrm{ppm}$, the output voltage of the sensor increases linearly with the sensitivity of $66.5 \mathrm{ppm}$ ( $\mathrm{KOH}$ solution) to $0.4 \mathrm{ppm}$ at best ( $\mathrm{KCl}$ solution) and the linearity $\left(\mathrm{R}^{2}\right)$ of more than $95 \%$. The increment of the content of the solution increases the dielectric constant of the solutions, hence, it increases the capacitance which is proportional to the output voltage. This study also found the ICF of each solution, which is not dependent on the concentration, but rather a characteristic of the specific material. The ICF of $\mathrm{LiCl}, \mathrm{NaCl}, \mathrm{KCl}, \mathrm{NaOH}, \mathrm{KOH}$ and $\mathrm{Pb}\left(\mathrm{NO}_{3}\right)_{2}$ solutions is $2.4 \mathrm{MHz}, 2.1 \mathrm{MHz}, 1.9 \mathrm{MHz}$, $1.5 \mathrm{MHz}, 1.1 \mathrm{MHz}$ and $490 \mathrm{kHz}$, respectively. This parallelplate capacitor sensor provides considerable advantages in monitoring the concentration, such as simplicity in design, low-cost fabrication, ease in handling and reliable measurement results.

\section{References}

${ }^{1}$ J. S. Wilson, Sensor Technology Handbook, (Elsevier Ltd, 2005).

${ }^{2}$ L. Cai, L. Song, P. Luan, Q. Zhang, N. Zhang, Q. Gao, D. Zhao, X. Zhang, M. Tu, F. Yang, W. Zhou, Q. Fan, J. Luo, W. Zhou, P. M. Ajayan and S. Xie, Super-stretchable, transparent carbon nanotube-based capacitive strain sensors for human motion detection, Sci. Rep. 3, 3048 (2013), doi: 10.1038/srep03048.
${ }^{3}$ S. Satyanarayana, D. T. McCormick and A. Majumdar, Parylene micro membrane capacitive sensor array for chemical and biological sensing, Sens. Actuators, B Chem. 115, 494 (2006), doi: 10.1016/j.snb.2005.10.013.

${ }^{4}$ M. Demori, V. Ferrari, D. Strazza and P. Poesio, A capacitive sensor system for the analysis of two-phase flows of oil and conductive water, Sens. Actuators, A Phys. 163, 172 (2010), doi: 10.1016/j.sna.2010.08.018.

${ }^{5}$ A. D. Hollingsworth and D. A. Saville, A broad frequency range dielectric spectrometer for colloidal suspensions: Cell design, calibration, and validation, J. Colloid Interf. Sci. 257, 65 (2003).

${ }^{6} \mathrm{~S}$. Bhat, Salinity (conductivity) sensor based on parallel plate capacitors, Graduate Theses and Dissertations, University of South Florida (2005).

${ }^{7}$ K. W. H. Shibata, M. Ito and M. Asakura, A digital hygrometer using a polyimide film relative humidity sensor, doi:https://doi. org/10.1109/19.492788.

${ }^{8}$ J. H. Nern and P. J. Schubert, A polyimide-based capacitive humidity sensor, IEEE Trans. Electron Devices. 32, 1220 (1985), doi:https://doi.org/10.1109/T-ED.1985.22104.

${ }^{9}$ L. D. G. Delapierre, H. Grange and B. Chambaz, Polymer-based capacitive humidity sensor: Characteristics and experimental results, Sens. Actuators. 4, 97 (1983).

${ }^{10}$ Y. Wang, S. Park, J. T. W. Yeow, A. Langner and F. Müller, A capacitive humidity sensor based on ordered macroporous silicon with thin film surface coating, Sens. Actuators, B Chem. 149, 136 (2010), doi: 10.1016/j.snb.2010.06.010.

${ }^{11}$ M. S. Cao, W. L. Song, Z. L. Hou, B. Wen and J. Yuan, The effects of temperature and frequency on the dielectric properties, electromagnetic interference shielding and microwave-absorption of short carbon fiber/silica composites, Carbon N. Y. 48, 788 (2010), doi: 10.1016/j.carbon.2009.10.028.

${ }^{12}$ R. N. Bracewell, The Fourier Transform and Its Applications (McGraw-Hill Book Company, 1986). 
${ }^{13}$ J. Fraden, Handbook of Modern Sensors: Physics, Designs, and Applications, 3rd edn. (Springer, 2004).

${ }^{14}$ D. J. C. Wood, Polarization Effects in Semiconductors: From ab Initio Theory to Device Applications (Springer, 2008).
${ }^{15}$ G. C. Stangle, Modelling of Materials Processing: An Approachable and Practical Guide (Springer, 1998).

${ }^{16}$ D. J. Willock, Molecular Symmetry (John Wiley \& Sons Ltd, 2009).

${ }^{17}$ J. M. Hollas, Modern Spectroscopy (Wiley, 1991). 